\title{
The roles of long-chain polyunsaturated fatty acids in pregnancy, lactation and infancy: review of current knowledge and consensus recommendations*
}

\author{
Berthold Koletzko ${ }^{1, \star *}$, Eric Lien², Carlo \\ Agostoni $^{3}$, Hansjosef Böhles ${ }^{4}$, Cristina \\ Campoy ${ }^{5}$, Irene Cetin 6 , Tamas Decsi ${ }^{7}$, Joachim \\ W. Dudenhausen ${ }^{8}$, Cristophe Dupont ${ }^{9}$, Stewart \\ Forsyth ${ }^{10}$, Irene Hoesli11, Wolfgang Holzgreve ${ }^{11}$, \\ Alexandre Lapillonne ${ }^{12}$, Guy Putet ${ }^{13}$, Niels J. \\ Secher ${ }^{14}$, Mike Symonds ${ }^{15}$, Hania Szajewska ${ }^{16}$, \\ Peter Willatts ${ }^{17}$ and Ricardo Uauy ${ }^{18}$ \\ 1 Department of Pediatrics, University of Munich, \\ Germany \\ 2 Department of Food Science and Human Nutrition, \\ University of Illinois, Urbana, USA \\ ${ }^{3}$ Department of Pediatrics, San Paolo Hospital, \\ University of Milan, Italy \\ ${ }^{4}$ Department of Pediatrics, University of Frankfurt, \\ Germany \\ ${ }^{5}$ Department of Pediatrics, University of Granada, \\ Spain \\ ${ }^{6}$ Department of Gynecology and Obstetrics, IRCCS \\ Policlinico, Mangiagalli and Regina Elena, University of \\ Milan, Italy \\ 7 University of Pecs, Pecs, Hungary \\ ${ }^{8}$ Department of Obstetrics, Charité-Universitätsmedizin \\ Berlin, Germany \\ ${ }^{9}$ Hopital St Vincent de Paul, Paris, France \\ 10 Department of Pediatrics, Ninewells Hospital and \\ Medical School, Dundee, UK \\ ${ }^{11}$ Department of Gynecology and Obstetrics, University \\ of Basel, Switzerland \\ ${ }^{12}$ Rene Descartes Paris 5 University, Paris, France and \\ Baylor College of Medicine, Houston, Texas, USA \\ ${ }^{13}$ Department of Pediatrics, Hôpital de la Croix Rousse, \\ Lyon, France
}

\footnotetext{
*This paper was worked out under the auspices of the WAPM to achieve consensus on issues in perinatal practice. Coordinator of the working group: Berthold Koletzko.

${ }^{* *}$ Corresponding author:

Berthold Koletzko, MD

Department of Pediatrics

Dr von Hauner Children's Hospital

University of Munich

Lindwurmstr. 4

D-80337 München

Germany

E-mail: Berthold.Koletzko@med.uni-muenchen.de
}

\author{
${ }^{14}$ Department of Gynecology and Obstetrics, Hvidovre \\ Hospital, Hvidore, Denmark \\ ${ }^{15}$ Academic Division of Child Health, Center for \\ Reproduction and Early Life, University of \\ Nottingham, UK \\ ${ }^{16}$ Department of Pediatrics, The Medical University of \\ Warsaw, Warsaw, Poland \\ 17 School of Psychology, University of Dundee, UK \\ ${ }^{18}$ Department of Human Nutrition, University of Chile, \\ Santiago, Chile, and London School of Hygiene and \\ Tropical Medicine, London, UK
}

\begin{abstract}
This paper reviews current knowledge on the role of the long-chain polyunsaturated fatty acids (LC-PUFA), docosahexaenoic acid (DHA, C22:6n-3) and arachidonic acid (AA, 20:4n-6), in maternal and term infant nutrition as well as infant development. Consensus recommendations and practice guidelines for health-care providers supported by the World Association of Perinatal Medicine, the Early Nutrition Academy, and the Child Health Foundation are provided. The fetus and neonate should receive LC-PUFA in amounts sufficient to support optimal visual and cognitive development. Moreover, the consumption of oils rich in n-3 LC-PUFA during pregnancy reduces the risk for early premature birth. Pregnant and lactating women should aim to achieve an average daily intake of at least $200 \mathrm{mg}$ DHA. For healthy term infants, we recommend and fully endorse breastfeeding, which supplies preformed LC-PUFA, as the preferred method of feeding. When breastfeeding is not possible, we recommend use of an infant formula providing DHA at levels between 0.2 and 0.5 weight percent of total fat, and with the minimum amount of $A A$ equivalent to the contents of DHA. Dietary LC-PUFA supply should continue after the first six months of life, but currently there is not sufficient information for quantitative recommendations.
\end{abstract}

Keywords: Alpha-linolenic acid; arachidonic acid; docosahexaenoic acid; eicosapentaenoic acid; infant nutrition; linoleic acid; maternal health; maternal nutrition; perinatal development. 


\section{Introduction}

Exceptionally rapid growth and development of the fetus occurs during pregnancy and for the young child during the first several years of life. Brain growth accelerates during the second half of pregnancy and remains high during the first year of life with continued growth for the next several years [23]. During this time many developmental milestones are reached in terms of cognitive, visual, and motor development. It is essential that high quality nutrition be supplied to the fetus, infant and young child to ensure that all essential nutrient needs are met. Breastfeeding should be promoted, protected and supported, initially as the sole source of nutrition and continuing upon the timely introduction of complimentary foods. If exclusive breastfeeding is not possible, the only appropriate substitute during the first year of life is an infant formula or a follow-on formula [52, 90]. The lipids of human milk and formula are of critical importance during this time period for several reasons. First of all, they are a major energy source to support appropriate growth. Both human milk and infant formula provide about half of their calories as fat. In addition, infants cannot synthesize omega-3 and omega- 6 polyunsaturated fatty acids (PUFA). These PUFA are required for normal growth and maturation of numerous organ systems, most importantly the brain and eye.

In 2001 the Child Health Foundation asked investigators in the field of LC-PUFA and perinatal development to review the available scientific data on LC-PUFA in infancy [52]. At that time, a consensus statement and recommendations for health-care providers on perinatal LC-PUFA supply were developed [51]. One of the recommendations of the 2001 workshop was to update the consensus statement and recommendations as additional data became available. More recently, a European Commission (EC) supported consensus group developed recommendations for dietary fat intakes for pregnant and lactating women, based on systematic literature reviews and a consensus conference held with international experts in the field [53]. The aim of the present publication is to review the recent literature and current recommendations regarding LC-PUFA as they pertain to maternal nutrition during pregnancy and lactation and term infant nutrition during the first months of life, and to provide updated recommendations for health-care providers. Based on analysis of the recent literature, the authors of this review who are involved in research in the areas of maternal and infant nutrition unanimously agreed on the conclusions and recommendations provided here, which are supported by the World Association of Perinatal Medicine (www.wapm.info), the Early Nutrition Academy (www.metabolic-programming.org/academy. htm), and the Child Health Foundation (www. kindergesundheit.de).

\section{Essential fatty acids}

Humans can synthesize saturated and monounsaturated fatty acids, but they cannot synthesize the $n-3$ and the n-6 families of PUFA. The parent fatty acids of these families, alpha-linolenic acid (18 carbons, three double bonds with the first double bond in the $n-3$ position, C18:3n-3, ALA) and linoleic acid (C18:2n-6, LA) are essential fatty acids and must be present in the diet. The fatty acids of these families cannot be interconverted, so both n-3 and n- 6 fatty acids are essential. ALA and LA are converted to longer chain, more highly unsaturated fatty acids through enzymatic chain elongation and desaturation. ALA is converted to eicosapentaenoic acid (C20:5n-3), then on to docosahexaenoic acid (C22:6n-3, DHA), whereas LA is converted to arachidonic acid (C20:4n-6, AA). DHA is a critical component of cell membranes, especially in the brain and the retina. AA is both a membrane component and a precursor to potent signaling molecules, the prostaglandins and leukotrienes. Figure 1 shows the pathway for conversion of ALA to $D H A$ and $L A$ to $A A$. The chain elongation/desaturation enzymes are shared by both n- 3 and n- 6 fatty acids with competition between substrates for these enzymes [15, 43].

\section{Fetal and infant LC-PUFA accumulation}

Brain accumulation of DHA starts in utero, with quantitatively marked deposition in the second half of gestation [20, 68, 69]. DHA accumulation in brain continues after birth, reaching a total brain DHA deposition of about $4 \mathrm{~g}$ between two and four years of age [68, 69]. DHA is also an important structural component of retina lipids, comprising as much as $50 \%$ of total fatty acids of rod and cone outer segments [82]. Unlike DHA, other n-3 LCPUFAs do not accumulate to any appreciable extent in the growing brain and eye [68]. Brain accumulation of AA also occurs during pre- and post-natal development.

Elongation and desaturation enzymes for PUFA conversion are present in the fetal liver early in gestation, but activity appears to be low before birth [86]. Therefore, the $n-6$ and n-3 LC-PUFA that the fetus accumulates in utero are derived predominantly through placental transfer, with the amounts in cord blood influenced by the maternal diet [55]. Both preterm and term infants are capable of synthesizing DHA and AA [18, 22, 74, 76]; conversion rates of $L A$ to $A A$ and of ALA to DHA are influenced by genetics, gender, and the amount of precursor fatty acids available in the diet [39]. Human milk always contains both AA and DHA, whereas, in the past, infant formulae had neither. Synthesis rates of these LCPUFA from C18 precursors are insufficient to maintain stable plasma and red blood cell LC-PUFA levels in 


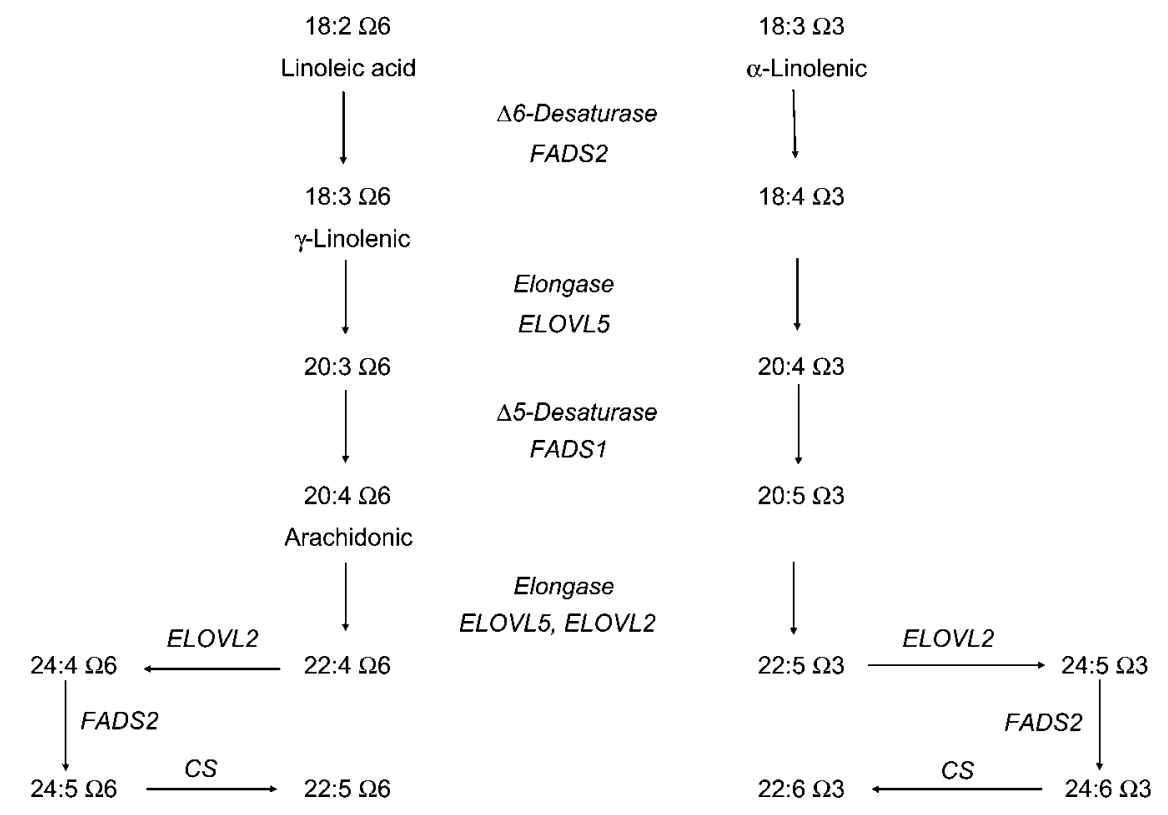

Figure 1 Metabolic conversion of the essential fatty acids linoleic acid (omega-6 series) and alpha-linolenic acid (omega-3 series) to long-chain polyunsaturated fatty acids (LC-PUFA) (Modified from Koletzko Larqué and Demmelmair, J Perinat Med. 2007).

infants receiving unsupplemented formula, and LC-PUFA levels decline in infants fed unsupplemented formula compared to those fed human milk (for example [4, 33]).

\section{Delivery of LC-PUFA to the fetus and infant}

\section{LC-PUFA during pregnancy}

Maternal dietary intake of LC-PUFA and lifestyle influence the LC-PUFA levels available for transfer to the fetus [4, 27, 35, 55]. The physiological importance of DHA is supported by its active and preferential maternalfetal placental transfer, which is mediated by specific fatty acid transfer proteins (FATP-1 and FATP-4) and membrane binding proteins that favor placental transport of DHA over other fatty acids such as LA [54, 59]. Sponsored by the European Commission, the Perinatal Lipid Nutrition Project (PeriLip) and The Early Nutrition Programming Project (EARNEST) in collaboration with several international scientific societies, recently developed consensus recommendations concerning dietary fat intake for pregnant and lactating women, based on a systematic review of available evidence and a formal consensus process [53]. The consensus document recommends an average DHA intake of at least 200 mg/day during both pregnancy and lactation. Women of childbearing age can meet the recommended intake of DHA by consuming one to two portions of sea fish per week, including fatty fish, which is a good source of n-3 LCPUFA. Consumption of this amount of fish does not gen- erally exceed the tolerable intake levels of environmental contaminants. Other sources of n-3 LC-PUFA include enriched foods and dietary supplements. Dietary ALA, the precursor to DHA, is much less effective in promoting optimal DHA status than consumption of preformed DHA and is insufficient to promote desirable levels of DHA deposition in the fetal brain [14, 34].

A number of studies have demonstrated that intake of fish, fish oils or single cell n-3 LC-PUFA oils during pregnancy result in slightly longer gestation, marginally higher birth weight, and reduced risk of preterm delivery $[42,53$, $65,83]$. Multiple pregnancies and closely spaced pregnancies create an even higher demand for maternal LCPUFA [71, 92]. A multinational epidemiological study indicated that higher concentrations of DHA in maternal milk and greater seafood consumption predict a lower prevalence of postpartum depression (PPD). The highest prevalence was found in South Africa (24.5\%) and the lowest in Japan (2\%) [37].

\section{LC-PUFA in lactation}

Human milk provides LA, ALA, DHA, AA, and other LCPUFA to breastfed infants. The level of $A A$ is relatively constant on a worldwide basis whereas the level of DHA is more variable and depends on maternal diet and lifestyle [1, 3, 67, 81, 91]. Population means of AA in human milk range between $0.35-0.7$ weight \% of total fatty acids [67, 81, 91], whereas means of DHA range from $0.17 \%$ to $1.0 \%$ of total fatty acids [91]. Lactating women supplemented with DHA have an increase in milk DHA 
levels [28, 48]. Gibson et al. [32] reported that a dosedependent relationship exists between maternal DHA consumption and DHA levels in human milk. In this study human milk DHA levels above $0.8 \%$ of total fatty acids did little to increase the plasma or RBC DHA content of the study infants.

\section{LC-PUFA in infant formulae}

Infants have been fed formulae with various concentrations and ratios of C18 PUFA, ALA and LA, in attempts to match the LC-PUFA status of breastfed infants (as measured by plasma or RBC LC-PUFA levels). Although DHA levels are marginally higher in infants fed formulae with a high ALA/LA ratio compared to groups fed lower ratios, they do not reach those found in breastfed infants, whereas AA levels are suppressed at high ALA/LA ratios $[19,47,63]$. Numerous studies have compared the LCPUFA levels in plasma and RBC of infants fed human milk, formulae supplemented with LC-PUFA or unsupplemented formula $[8,33]$. Circulating levels of both DHA and $A A$ in breastfed infants can only be matched with the addition of both of these fatty acids to formula. Provision of $n-3$ LC-PUFA without AA in infant formula may reduce circulating $A A$ in preterm infants $[39,50,57]$ and in term infants [56] and may thus negatively affect growth in these infants $[16,58,73]$.

\section{Infant outcomes}

\section{Dietary LC-PUFA during infancy and visual development}

Infants are born with a poorly developed visual system, but during the first year of life vision develops rapidly [ 75 , 87]. Measures of visual development typically involve either electrophysiological measures (visual evoked potential, VEP) or forced choice preferential looking (FPL). Methodological differences are important since electrophysiological evaluations are more sensitive than FPL, and therefore, are capable of detecting smaller differences between groups [84].

Numerous studies have evaluated the effect of DHA status on the developing visual system. Malcolm et al. [66] provided fish oil during pregnancy and found that the DHA status of the infants at birth was related to the maturity of visual evoked potential at 2.5 and six months of age. Eye-hand coordination at the age of 2.5 years is improved in infants whose mothers received high dose fish oil during pregnancy [24]. Observational studies found that human milk DHA levels were positively correlated to visual development in breast-fed infants [44, 49]. Studies which evaluated lactating women receiving either an n-3 LC-PUFA supplement or placebo did not find a difference between groups [33, 48,61], although several studies identified a significant positive correlation between visual acuity and milk DHA levels or infant DHA status [33,61]. Other studies have evaluated the effect of infant formula LC-PUFA supplementation on visual development with infants receiving supplemented infant formula from shortly after birth for various amounts of time. Some studies report positive results, whereas others find no statistically significant difference between formula groups (reviewed in [30, 75, 79]). A number of the studies reporting no positive LC-PUFA effects were conducted with very low DHA levels.

Two studies have evaluated the role of the provision of LC-PUFA during the second six months of life with formula or complementary foods on visual development, and these studies found improved vision when infants received LC-PUFA during this time compared to controls $[40,41]$.

Three studies have examined the potential long term benefits of LC-PUFA supplemented formulae. One study did not find an improvement in stereo-acuity at 4-6 years of age when infants received an LC-PUFA fortified formula [80]. A second study found no differences between breastfed infants, or infants receiving either LC-PUFA fortified formula or control formula at 39 months of age [5]. In a third study infants received various formulae (control formula, formula containing DHA alone, formula containing $A A$ and $D H A$ ), or were breastfed for 17 weeks and were assessed at four years of age for vision and IQ. Both vision and IQ were significantly poorer in the control group compared to breastfed infants, whereas no such differences were found when the fortified formula groups were compared to the breastfed group [9].

A Cochrane review [79] did not find a significant relationship between DHA supplementation and vision or general development in infants; however, the author noted that a benefit of increased dietary LC-PUFA on information processing was possible. One problem with the evaluation of the published studies is the wide range of LC-PUFA levels evaluated (from 0.1 weight \% DHA to $0.36 \%$ DHA). Two groups $[60,87]$ have developed models in which infant DHA status is related to dietary ALA (and assumed subsequent conversion to DHA) and dietary DHA. These models demonstrated a positive correlation between visual development and dietary n-3 fatty acid intake.

\section{Dietary LC-PUFA during infancy and cognitive development}

Given that the predominant $n-3$ and $n-6$ fatty acids in brain are DHA and AA, it is reasonable to consider the effects of maternal supplementation with DHA during pregnancy and lactation or LC-PUFA in infant formula on cognitive development. Studies have employed a variety of tests, such as a test of general developmental (e.g., the Bayley Scales of Infant Development) and psychomotor development (Brunet-Lezine test), and more specific evaluations, such as problem solving and language 
development tests. Each of these measures assesses different components of brain development; therefore inconsistent results might not be surprising [17, 70, 88].

Epidemiological evidence reports an association between higher levels of maternal fish consumption during pregnancy and developmental outcomes. Higher maternal fish consumption during pregnancy resulted in short term benefits for infants (higher novelty preference on visual recognition memory [72], and longer term benefits (higher scores of verbal intelligence quotient and other behavioral outcome measures in the children up to an age of eight years [38]. In breastfed infants, DHA status at two months of age correlated with language production and comprehension at 14 and 18 months of age $[44,45]$. Jensen et al. [48] evaluated measures of cognitive development among infants of lactating women supplemented for four months after delivery with either DHA (200 mg/day) or control vegetable oil and assessed development. At 30 months of age, a significant increase in Bayley Psychomotor Development Index was found, although no differences were found in vision or the Bayley Mental Development Index during the study.

In a double blind randomized trial, maternal supplementation during pregnancy and lactation with cod liver oil providing about $1.2 \mathrm{~g}$ DHA and $0.8 \mathrm{~g}$ EPA led to a $4 \%$ point advantage in children's scores on the Kaufmann $A B C$ test (a standardized intelligence test) in the subgroup of children tested at the age of four years [36]. Two other studies during lactation have not demonstrated significant improvements in cognitive development $[28,48]$ and one study reported a transient decrease in vocabulary comprehension at one year of age, but not at two years [62]. However, controlling all the variables in evaluations of breast-feeding and cognitive development is difficult.

Mixed results have been found in infant formula studies. Some studies have demonstrated significant benefits in cognitive development when infants have received LCPUFA containing formulae, while other studies have not $[30,70,75]$. As noted above, a Cochrane review [79] found that information processing may be improved by dietary LC-PUFAs. As with studies measuring visual response, studies employing $<0.2 \% \mathrm{DHA}$ generally did not report positive effects.

Motor development may be influenced by early LCPUFA supply. Spontaneous motor behavior of infants, reported as a set of parameters termed general movements, measures nervous system organization early in life. Following two months of formula feeding with or without LC-PUFA, or breastfeeding, the infants who had been randomized to be fed unsupplemented formula had a higher proportion of abnormal spontaneous general movements [10]. At 18 months of age the groups did not differ in either Bayley Scales of Infant Development or Hempel scores, a standardized assessment technique for the detection of minor signs of neurological dysfunction
[11]. Maternal fatty acid status (measured by umbilical cord blood fatty acid analysis) and neurological development was also assessed by Bouwstra and colleagues. At three months of age infants born to mothers with low AA status had significantly higher levels of abnormal general movement scores [12] and low DHA status at birth was associated with lower Hempel scores at 18 months [13]. In a randomized trial the intake of high dosages of fish oil providing $2.2 \mathrm{~g}$ DHA and $1.1 \mathrm{~g}$ EPA per day to women during the second half or pregnancy led to improved eye-hand coordination of the children at the age of 2.5 years [26]. Thus, both perinatal status and post-natal supply of LC-PUFA may contribute to infant development.

\section{Other effects of LC-PUFA}

Dietary supplementation of infant formula with DHA and AA has been associated with lower blood pressure at the age of six years [31]. Compared with children given unsupplemented infant formula during the first four months of life, those fed formula with DHA and AA had significantly lower mean blood pressure (mean difference: $-3.0 \mathrm{~mm} \mathrm{Hg}$ ) and diastolic blood pressure (mean difference: $-3.6 \mathrm{~mm} \mathrm{Hg}$ ) at six years of age. Since blood pressure tends to track from childhood into adult life, early exposure to dietary LC-PUFA might have lasting effects on reduced blood pressure and cardiovascular risk.

There are also indications that early LC-PUFA provision may modulate immune response. Infants born to atopic pregnant women who were randomized to receive a high dosage marine oil supplement during the second half of pregnancy demonstrated an improved response to antigen skin prick test at age one year and less severe atopic dermatitis compared to infants whose mothers received placebo [25]. A study in preterm infants demonstrated that lymphocyte populations, cytokine production and antigen maturity were similar between infants receiving human milk and an LC-PUFA supplemented formula, whereas infants receiving an unsupplemented formula differed in all these parameters [29].

One study has demonstrated that maternal and cord blood LC-PUFA status is predictive of bone mass in healthy term infants [89].

\section{Means of increasing LC-PUFA intake for mothers and infants}

Numerous studies have evaluated the effects and safety of LC-PUFA supply to pregnant and lactating women [43]. These studies have taken into account the use of DHA alone or fish oils with various levels of DHA and EPA. Fish consumption may increase the exposure of the mother and fetus to contaminants such as methylmercury, dioxins and polychlorinated biphenyls (PCB) and 
also increase the levels of these contaminants in breast milk. The European Food Safety Authority has evaluated this subject and concluded that women of childbearing age consuming two fish meals per week (the recommended level during pregnancy and lactation) should generally not exceed the provisional tolerable weekly intake of environmental pollutants. The recent cohort studies reporting a positive relationship between higher sea fish consumption by pregnant women and improved child cognition, verbal intelligence quotient, fine motor coordination and prosocial behavior [38, 72] support the conclusion that the beneficial effects of higher n-3 LCPUFA supply from sea fish on child development outweigh the potential disadvantages from increased intakes of contaminants [53].

Sources of LC-PUFA during the first year of life include human milk, infant or follow-on formula enriched with LCPUFA and complementary foods such as egg, fatty fish, and meat. Safety is of primary importance. Highly refined oils from single cell organisms (specific algal and fungal organisms), eggs, or fish as sources of DHA and/or AA are appropriate for use in infant formulae and weaning foods if the purity and safety of the specific oil used has been documented. A systematic review of effects of LCPUFA supplementation of infant formulae on infant weight gain, based on original data analysis, indicates that the addition of both DHA and AA to infant formula supports growth comparable to that seen in infants fed unsupplemented formula [64]. A limited number of studies with infant formula supplemented with DHA alone also seemed to produce acceptable weight gain in term infants [64], but the available data seem too limited to draw final conclusions.
If LC-PUFAs are added to formulae, the combined addition of DHA and AA appears appropriate. The relative constancy of $A A$ supply to the infant through breastfeeding [91] clearly demonstrates that breastfed infants will receive both AA and DHA. LC-PUFAs are the precursors to eicosanoids, highly bioactive oxygenated derivatives of their parent LC-PUFAs. AA is the predominant precursor fatty acid, due to its high concentration in membrane phospholipids. AA can be oxygenated by three different enzymatic systems: cyclooxygenases (forming prostaglandins and thromboxane), lipoxygenases (forming leukotrienes) and cytochrome P450 monooxygenases (forming 19- and 20 HETE). The biological activities of the eicosanoids are extensive. For example, one prostaglandin, $\mathrm{PGE}_{2}$, affects the vasculature, airways, stomach, kidney, neutrophils, lymphocytes, and pain perception. Sellmayer and Koletzko [78] have reviewed the roles of eicosanoids in infants. A large database exists concerning not only the safety, but also the efficacy, of infant formula containing both AA and DHA. These facts, together, support the addition of both $A A$ and DHA when LC-PFUAs are added to formula.

Brain development continues during early childhood, indicating the continued need for adequate intakes of DHA and AA. With the introduction of complementary foods, infants consume less breast milk or formula, and the total dietary intake of LC-PUFA may decrease unless the introduced foods contain LC-PUFA. Regular intakes of egg yolk, fish, liver or other LC-PUFA fortified foods may be advisable [46], but the exact requirements for LC-PUFA for older infants and toddlers are not known. Since the dietary supply of LC-PUFA might be beneficial for continued optimal neurological function in childhood

Table 1 Conclusions and recommendations on Dietary fat intakes for pregnant and lactating women of the EU supported the Perinatal Lipid Intake Working Group (from Koletzko et al. [53]).

1. Dietary fat intake during pregnancy and lactation, as a proportion of energy intake, should be the same as that recommended for the general population

2. The omega-3 long-chain polyunsaturated fatty acid (n-3 LC-PUFA), docosahexaenoic acid (DHA), must be deposited in adequate amounts in brain and other tissues during fetal and early postnatal life. Several studies have shown an association between maternal dietary intake of fatty fish, or oils providing n-3 LC-PUFA during pregnancy and/or lactation and visual and cognitive development as well as other functional outcomes of the infants. Pregnant and lactating women should aim to achieve a dietary intake of n-3 LC-PUFA that supplies a DHA intake of at least $200 \mathrm{mg} /$ day. Intakes of up to $1 \mathrm{~g} / \mathrm{day}$ of DHA or $2.7 \mathrm{~g} /$ day of $\mathrm{n}-3$ LC-PUFA have been used in randomized trials without occurrence of significant adverse effects

3. Women of childbearing age can meet the recommended intake of DHA by consuming one to two portions of sea fish per week, including fatty fish, which is a good source of n-3 LC-PUFA. This intake of fatty fish rarely exceeds the tolerable intake of environmental contaminants. Dietary fish should be selected from a wide range of species without undue preference for large predatory fish, which are more likely to be contaminated with methylmercury

4. Intake of the precursor, alpha-linolenic acid, is far less effective with respect to DHA deposition in fetal brain than the intake of preformed DHA

5. There is no evidence that women of childbearing age whose dietary intake of linoleic acid is adequate need an additional dietary intake of arachidonic acid

6. Some studies have shown that maternal intake of fish, fish oils or n-3 LC-PUFA results in a slightly longer duration of gestation, a somewhat higher birth weight and a reduced risk of early preterm delivery. The clinical importance of such effects with respect to infant health has not been fully elucidated

7. Screening for dietary inadequacies should be performed during pregnancy, preferably during the first trimester. If less than desirable dietary habits are detected, individual counselling should be offered during pregnancy as well as during lactation 
Table 2 Recommended LC-PUFA supply with infant formula and baby foods.

1. The available evidence strongly supports benefits of adding DHA and AA to infant formula.

2. DHA should reach at least $0.2 \%$ of fatty acids and not exceed $0.5 \%$ of fatty acids.

3. Levels of added AA should at be least equal to those of added DHA.

4. The amount of EPA added should not exceed the amount of added DHA.

5. It appears advisable to continue the provision of dietary sources of LC-PUFA during the second six months of life, but optimal amounts cannot be specified at this time

$[2,6,7]$, the use of infant/toddler foods providing DHA and AA should be further evaluated.

\section{Recommendations for LC-PUFA for pregnant and lactating women}

Recent European Commission supported consensus recommendations based on systematic literature reviews and an expert consensus process include the advice that pregnant and lactating women should aim at achieving an average DHA intake of at least $200 \mathrm{mg}$ per day (Tables 1 and 2).

\section{Recommendations for LC-PUFA for infants}

In agreement with other reports, the authors of this review strongly endorse breastfeeding as the preferred method of feeding healthy infants. They also emphasize, however, the importance of the provision of a balanced dietary intake for breastfeeding women, and this should include a regular supply of DHA. This review considered the present guidelines from an ESPGHAN coordinated International Expert Group providing recommendations on the composition of infant formula, the Codex Alimentarius proposal for a global infant formula standard, and the EU Commission Directive on infant formula and follow-on formula [21, 52, 85]. The authors of this review conclude that the available evidence supports the addition of DHA to infant formula. The addition of at least $0.2 \%$ of fatty acids as DHA appears necessary for achieving a benefit on functional endpoints, but DHA levels should not exceed $0.5 \%$ of fatty acids because systematic evaluation of higher levels of intake have not been published (Table 2). Based on current knowledge, infant formula contents of AA should be at least those of added DHA, and EPA should not exceed levels of DHA. Dietary LC-PUFA supply should continue during the second six months of life, but there is currently not sufficient information for quantitative recommendations for addi- tion of LC-PUFA to follow-on formula or complementary foods.

\section{Recommendations for future LC-PUFA research}

- Future research should consider short- and long-term effects of LC-PUFA status prior to and during pregnancy, lactation, and infancy according to inter-individual differences, such as genetic variation in fatty acid desaturase activities or gender.

- Studies addressing subgroups with potential specific needs and benefits, such as women with at risk pregnancies, restricted dietary intakes, or short time intervals between pregnancies are encouraged.

- Supplementation studies should aim to examine growth, body composition and bone mineralization, visual and cognitive development, as well as effects on immune outcomes (such as allergy and inflammatory disorders), and cardiovascular function.

- Studies evaluating different amounts of LC-PUFA, and the specific effects of AA supply, with sufficient duration of intake, adequate sample sizes, and standardized methodology for outcome measurements need careful consideration.

- Infant formula studies should consider various levels of DHA in order to determine possible dose-response relationships and to elucidate potential immediate and long-term benefits.

- Dose-response studies of LC-PUFA intake during the second six months of life should be undertaken.

- Simplified measures of dietary supply and of LC-PUFA status should be developed and evaluated.

\section{Acknowledgements}

The conclusions and recommendations developed by this group reflect only the opinions and consensus of its members. The scientific workshop held at Barcelona was financially supported by Martek Biosciences Corporation. BK is the recipient of a Freedom to Discover Award of the Bristol Myers Squibb Foundation, New York, NY, USA.

\section{References}

[1] Agostoni C, Marangoni F, Giovannini M, Riva E, Galli C. Long-chain polyunsaturated fatty acids, infant formula, and breastfeeding. (Letter) Lancet. 1998;352:1703-4.

[2] Agostoni C, Massetto N, Biasucci G, Rottoli A, Bonvissuto $M$, Bruzzese MG, et al. Effects of long-chain polyunsaturated fatty acid supplementation on fatty acid status and visual function in treated children with hyperphenylalaninemia. J Pediatr. 2000;137:504-9. 
[3] Agostoni C, Marangoni F, Grandi F, Lammardo AM, Giovannini M, Riva E, et al. Earlier smoking habits are associated with higher serum lipids and lower milk fat and polyunsaturated fatty acid content in the first six months of lactation. Eur J Clin Nutr. 2003;57:1466-72.

[4] Agostoni C, Galli C, Riva F, Colombo C, Giovannini M, Marangoni F. Reduced docosahexaenoic acid synthesis may contribute to growth restriction in infants born to mothers who smoke. J Pediatr. 2005;147:854-6.

[5] Auestad N, Scott DT, Janowsky JS, Jacobsen C, Carroll $\mathrm{RE}$, Montalto MB, et al. Visual, cognitive and language assessments at 39 months: a follow-up study of children fed formulas containing long-chain polyunsaturated fatty acids to 1 year of age. Pediatrics. 2003;112:e177-83.

[6] Beblo S, Reinhardt H, Muntau AC, Mueller-Felber W, Roscher AA, Koletzko B. Fish oil supplementation improves visual evoked potentials in children with phenylketonuria. Neurology. 2001;57:1488-91.

[7] Beblo S. Reinhardt H, Demmelmair H, Muntau AC, Koletzko B. Effect of fish oil supplementation on fatty acid status, coordination, and fine motor skills in children with phenylketonuria. J Pediatr. 2007;150:479-84.

[8] Birch EE, Hoffman DR, Uauy R, Birch DG, Prestidge C. Visual acuity and the essentiality of docosahexaenoic acid and arachidonic acid in the diet of term infants. Pediatr Res. 1998;44:201.

[9] Birch EE, Garfield S, Castaneda Y, Hughybanks-Wheaton D, Uauy R, Hoffman D. Visual acuity and cognitive outcomes at 4 years of age in a double-blind, randomized trial of long-chain polyunsaturated fatty acid-supplemented infant formula. Early Hum Dev. 2007;

[10] Bouwstra H, Dijck-Brouwer DJ, Wildeman JA, Tjoonk HM, van der Heide JC, Boersma ER, et al. Long-chain polyunsaturated fatty acids have a positive effect on the quality of general movements of healthy term infants. Am J Clin Nutr. 2003;78:313.

[11] Bouwstra H, Dijck-Brouwer DJ, Boehm G, Boersma ER, Muskiet FAJ, Hadders-Algra M. Long-chain polyunsaturated fatty acids and neurological developmental outcome at 18 months in healthy term infants. Acta Paediatr. 2005; 94:26-32.

[12] Bouwstra H, Dijck-Brouwer DJ, Decsi T, Boehm G, Boersma ER, Muskiet FAJ, et al. Relationship between umbilical cord essential fatty acid content and the quality of general movements of healthy term infants at 3 months. Ped Res. 2006a;59:717-22.

[13] Bouwstra H, Dijck-Brouwer DJ, Decsi T, Boehm G, Boersma ER, Muskiet FAJ, et al. Neurologic condition of healthy term infants at 18 months: positive association with venous umbilical DHA status and negative association with umbilical trans-fatty acids. Ped Res. 2006b;60:1-7.

[14] Brenna JT. Efficiency of conversion of alpha-linolenic acid to long chain n-3 fatty acids in man. Curr Opin Clin Nutr Metab Care. 2002;5:127-32.

[15] Burdge GC, Calder PC. Conversion of alpha-linolenic acid to longer-chain polyunsaturated fatty acids in human adults. Reprod Nutr Dev. 2005;45:581-97.

[16] Carlson SE, Werkman SH, Tolley EA. Effect of long-chain n-3 fatty acid supplementation on visual acuity and growth of preterm infants with and without bronchopulmonary dysplasia. Am J Clin Nutr. 1996;63:687.

[17] Carlson SE, Neuringer M. Polyunsaturated fatty acid status and neurodevelopment: a summary and critical analysis of the literature. Lipids. 1999;34:171-78.
[18] Carnielli VP, Wattimena DJL, Luijendijk IHT, Boerlage A, Degenhart HJ, Sauer PJJ. The very low birth weight premature infant is capable of synthesizing arachidonic and docosahexaenoic acids from linoleic and linolenic acids. Pediatr Res. 1996;40:169.

[19] Chirouze V, Lapillonne A, Putet G, Salle BL. Red blood cell fatty acid composition in low-birth-weight infants fed either human milk or formula during the first months of life. Acta Paediatr Suppl. 1994;405:70-7.

[20] Clandinin MT, Chappell JE, Leong S, Heim T, Sawyer PR, Chance GW. Extrauterine fatty acid accretion in infant brain: implication for fatty acid requirements. Early Hum Dev. 1980;131:

[21] Codex Alimentarius Commission. Report of the $28^{\text {th }}$ Session of the CODEX Committee on Nutrition and Foods For Special Dietary Uses. Codex Alimentarius Commission, 30 October-3 November 2006.

[22] Demmelmair H, Schenck UV, Behrendt E, Sauerwald T, Koletzko B. Estimation of arachidonic acid synthesis in full term neonates using natural variation of ${ }^{13} \mathrm{C}$ content. $\mathrm{J}$ Pediatr Gastroenterol Nutr. 1995;21:31.

[23] Dobbing J. The later development of the brain and its vulnerability. In: Davis JA, Dobbing J, editors. London: Scientific Foundations of Paediatrics, William Heinemann Medical Books, Ltd; 1994. p. 565-77.

[24] Dunstan JA, Mori TA, Barden A, Beilin JT, Taylor AL, Holt $P G$, et al. Fish oil supplementation in pregnancy modifies neonatal allergen specific immune responses and clinical outcomes in infants at high risk of atopy: a randomized, controlled trial. J Allergy Clin Immunol. 2003;112:1178-84.

[25] Dunstan JA, Prescott SL. Does fish oil supplementation in pregnancy reduce the risk of allergic disease in infants? Curr Opin Allergy Clin Immunol. 2005;5:215-21.

[26] Dunstan JA, Simmer K, Dixon G, Prescott SL. Cognitive assessment at $2 \frac{1}{2}$ year following fish oil supplmentation in pregnancy: a randomized controlled trial. Arch Dis Child Fetal Neonatal Ed. 2006; Dec 21 Epub.

[27] Dutta-Roy AK. Transport mechanisms for long-chain polyunsaturated fatty acids in the human placenta. Am J Clin Nutr. 2000;71:315S.

[28] Fidler N, Sauerwald T, Pohl A, Demmelmair H, Koletzko B. Docosahexaenoic acid transfer into human milk after dietary supplementation: a randomized clinical trial. J Lipid Res. 2000;41:1376.

[29] Field CJ, Thomson CA, Van Aerde JE, Parrott A, Euler A, Lien $\mathrm{E}$, et al. Lower proportion of $\mathrm{CD} 45 \mathrm{RO}^{+}$cells and deficient interleukin-10 production by formula-fed infants, compared with human-fed, is corrected with supplementation of long-chain polyunsaturated fatty acids. J Pediatr Gastro Nutr. 2000;31:291.

[30] Fleith M, Clandinin MT. Dietary PUFA for preterm and term infants: review of clinical studies. Crit Rev Food Sci and Nutr. 2005;45:205-29.

[31] Forsyth JS, Willatts P, Agostoni C, Bissenden J, Casaer P, Boehm G. Long chain polyunsaturated fatty acid supplementation in infant formula and blood pressure in later childhood: follow up of a randomized controlled trial. $\mathrm{Br}$ Med J. 2003;953-doi:10.1136/bmj.326.7396.953.

[32] Gibson RA, Neumann MA, Makrides M. Effect of increasing breast milk docosahexaenoic acid on plasma and erythrocyte phospholipid fatty acids and neural indices of exclusively breast fed infants. Eur J Clin Nutr. 1997;51: S78-84.

[33] Gibson RA, Makrides M, Hawkes JS, Neumann MA, Euler AR. A randomized trial of arachidonic acid dose in for- 
mulas containing docosahexaenoic acid in term infants. In: Riemersma RA, et al., editors. Essential fatty acids and eicosanoids: invited papers from the Fourth International Congress. Champaign, IL: AOCS Press; 1998. pp. 147153.

[34] Greiner RC, Winter J, Nathanielsz PW, Brenna JT. Brain docosahexaenoate accretion in fetal baboons: bioequivalence of dietary alpha-linolenic and docosahexaenoic acids. Pediatr Res. 1997;426:826-34.

[35] Haggarty P. Placental regulation of fatty acid delivery and its effect on fetal growth - a review. Placenta. 2002;23 Suppl A:S28-38.

[36] Helland IB, Smith L, Saarem K, Saugstad OD, Drevon CA. Maternal supplementation with very-long-chain n-3 fatty acids during pregnancy and lactation augments children's IQ at 4 years of age. Pediatr. 2003;111:e39.

[37] Hibbeln JR. Seafood consumption, the DHA content of mothers' milk and prevalence rates of postpartum depression: a cross-national, ecological analysis. J Affect Disord. 2002;69:15-29.

[38] Hibbeln JR, Davis JM, Steer C, Emmett P, Rogers I, Williams $C$, et al. Maternal seafood consumption in pregnancy and neurodevelopmental outcomes in childhood (ALSPAC study): an observational cohort study. Lancet. 2007;369: 578.

[39] Hoffman DR, Birch EE, Birch DG, Uauy R, Castaneda YS, Lapus MG, et al. Impact of early dietary intake and blood lipid composition of long-chain polyunsaturated fatty acids on later visual development. J Pediatr Gastroenterol Nutr. 2000;31:540.

[40] Hoffman DR, Birch EE, Yolanda SC, Fawcett SL, Wheaton $\mathrm{DH}$, Birch DG, et al. Visual function in breast-fed term infants weaned to formula with or without long-chain polyunsaturated at 4 to 6 months: a randomized clinical trial. J Pediatr. 2003;142:669.

[41] Hoffman DR, Theuer RC, Castaneda YS, Wheaton DH, Bosworth RG, O'Connor AR, et al. Maturation of visual acuity is accelerated in breast-fed infants fed baby food containing DHA-enriched egg yolk. J Nutr. 2004;124: 2307-13.

[42] Horvath A, Koletzko B, Szajewska H. Effect of supplementation of women in high-risk pregnancies with long-chain polyunsaturated fatty acids on pregnancy outcomes and growth measures at birth: a meta-analysis of randomized controlled trials. Br J Nutr. 2007;98:253-9.

[43] Innis SM. Essential fatty acid transfer and fetal development. Placenta. 2005;26:S70-5.

[44] Innis SM, Gilley J, Werker J. Are human-milk long-chain polyunsaturated fatty acids related to visual and neural development in breast-fed infants? J Pediatr. 2001;39:532.

[45] Innis SM, Gilley J, Werker J. N-3 docosahexaenoic acid is related to measures of visual and neural development in breast-fed infants to 14 months of age. Am J Clin Nutr. 2002;75:406S.

[46] Jackson KA, Gibson RA. Weaning foods cannot replace breast milk as sources of long-chain polyunsaturated fatty acids. Am J Clin Nutr. 1989;50:980.

[47] Jensen CL, Chen H, Fraley JK, Anderson RE, Heird WC. Biochemical effects of dietary linoleic/ $\alpha$-linolenic acid ratio in term infants. Lipids. 1996;31:107.

[48] Jensen DL, Voigt RG, Prager TC, Zou YL, Fraley JK, Rozelle JC, et al. Effects of maternal docosahexaenoic acid intake on visual function and neurodevelopment in breastfed term infants. Am J Clin Nutr. 2005;82:125-32.
[49] Jorgensen MH, Hernell O, Hughes EL, Michaelsen KF. Is there a relation between docosahexaenoic acid concentration in mothers' milk and visual development in term infants? J Pediatr Gastro Nutr. 2001;32:293.

[50] Koletzko B, Schmidt E, Bremer HJ, Harzer G. Effects of dietary long-chain polyunsaturated fatty acids on the essential fatty acid status of premature infants. Eur $\mathrm{J}$ Pediatr. 1989;669.

[51] Koletzko B, Agostini C, Carlson SE, Clandinin T, Hornstra $G$, Neuringer $M$, et al. Long chain polyunsaturated fatty acids (LC-PUFA) and perinatal development. Acta Paediatr. 2001;90:460.

[52] Koletzko B, Baker S, Cleghorn G, Neto UF, Gopalan S, Hernell O, et al. Global standard for the composition of infant formula: recommendations of an ESPGHAN coordinated international expert group. J Pediatr Gastroenterol Nutr. 2005;41:584-99.

[53] Koletzko B, Cetin I, Brenna J, for the Perinatal Lipid Intake Working Group. Dietary fat intakes for pregnant and lactating women. $\mathrm{Br} J$ Nutr. 2007; doi:10.1017/ S0007114507764747.

[54] Koletzko B, Larque E, Demmelmair H. Placental transfer of long-chain polyunsaturated fatty acids (LC-PUFA). J Perinat Med. 2007;35:S5-11.

[55] Krauss-Etschmann S, Shadid R, Campoy C, Hoster E, Demmelmair $\mathrm{H}$, Jiménez $\mathrm{M}$, et al. Fish oil and folate supplementation of pregnant women and maternal and fetal DHA and EPA plasma levels - a randomized European multicenter trial. Am J Clin Nutr. 2007;85:1392-400.

[56] Lapillonne A, Brossard N, Claris O, Reygrobellet B, Salle BL. Erythrocyte fatty acid composition in term infants fed human milk or a formula enriched with a low eicosapentanoic acid fish oil for 4 months. Eur J Pediatr. 2000; 159:49-53.

[57] Lapillonne A, Picaud JC, Chirouze V, Goudable J, Reygrobellet $\mathrm{B}$, Claris $\mathrm{O}$, et al. The use of low-EPA fish oil for long-chain polyunsaturated fatty acid supplementation of preterm infants. Pediatric Res. 2000;48:835-41.

[58] Lapillonne A, Carlson SE. Polyunsaturated fatty acids and infant growth. Lipids. 2001;36:901-11.

[59] Larqué E, Demmelmair H, Klingler M, De Jonge S, Bondy $B$, Koletzko B. Expression pattern of fatty acid transport protein-1 (FATP-1), FATP-4 and heart-fatty acid binding protein $(\mathrm{H}-\mathrm{FABP})$ genes in human term placenta. Early Hum Dev. 2006;82:697-701.

[60] Lauritzen L, Hansen HS, Jorgensen MH, Michaelsen KF. The essentiality of long chain $n-3$ fatty acids in relation to development and function of the brain and retina. Prog Lipid Res. 2001;40:1-94.

[61] Lauritzen L, Jorgensen MH, Mickelsen TB, Skovgaard IM, Straarup E, Olsen SF, et al. Maternal fish oil supplementation in lactation: effect on visual acuity and n-3 fatty acid content of infant erythrocytes. Lipids. 2004;39:195-206.

[62] Lauritzen L, Jorgensen MH, Olsen SF, Straarup EM, Michaelsen KF. Maternal fish oil supplementation in lactation: effect on developmental outcome in breast-fed infants. Reprod Nutr Dev. 2005;45:535-47.

[63] Makrides M, Neumann MA, Jeffrey B, Lien EL, Gibson RA. A randomized trial of different ratios of linoleic to alphalinolenic acid in the diet of term infants: effects on visual function and growth. Am J Clin Nutr. 2000;71:120.

[64] Makrides M, Gibson RA, Udell T, Reid K, International LCPUFA Investigators. Supplementation of infant formula with long chain polyunsaturated fatty acids does not influ- 
ence the growth of term infants. Am J Clin Nutr. 2005;81: 1094.

[65] Makrides M, Duley L, Olsen SF. Marine oil, and other prostaglandin precursor, supplementation for pregnancy uncomplicated by pre-eclampsia or intrauterine growth restriction. Cochrane Database Syst Rev. 2006;3: CD003402.

[66] Malcolm CA, McCulloch DL, Montgomery C, Shepherd A, Weaver LT. Maternal docosahexaenoic acid supplementation during pregnancy and visual evoked potential development in term infants; a double blind prospective, randomized trial. Arch Dis Child Fetal Neonatal Ed. 2003; 88:F383.

[67] Marangoni F, Agostini C, Lammardo AM, Bonvissuto M, Giovannini M, Galli C, et al. Polyunsaturated fatty acids in maternal plasma and in breast milk. Prostaglandins Leukot Essent Fatty Acids. 2002;66:535.

[68] Martinez M. Tissue levels of polyunsaturated fatty acids during early human development. J Pediatr. 1992;120: S129.

[69] Martinez M. Polyunsaturated fatty acids in the developing human brain, red cells and plasma: influence of nutrition and peroxisomal disease. J World Rev Nutr Diet. 1994; 75:70.

[70] McCann JC, Ames BN. Is docosahexaenoic acid, an n-3 long-chain polyunsaturated fatty acid, required for development of normal brain function? An overview of evidence from cognitive and behavioral tests in human and animals. Am J Clin Nutr. 2005;82:281-95.

[71] McFayden M, Farquharson J, Cockburn F. Maternal and umbilical erythrocyte omega- 3 and omega- 6 fatty acids and haemorheology in singleton and twin pregnancies. Arch Dis Child Fetal Neonatal Ed. 2003;88:F134.

[72] Oken E, Wright RO, Kleinman KP, Bellinger D, Amarasiriwardena $\mathrm{CJ}, \mathrm{Hu} \mathrm{H}$, et al. Maternal fish consumption, hair mercury, and infant cognition in a U.S. Cohort. Environ Health Perspect. 2005;113:1376-80.

[73] Ryan AS, Montalto MB, Groh-Wargo S, Mimouni F, Sentipal-Walerius $J$, Doyle $J$, et al. Effect of DHA-containing formula on growth of preterm infants to 59 weeks postmenstrual age. Am J Hum Biol. 1999;11:457.

[74] Salem Jr N, Wegher B, Mena P, Uauy R. Arachidonic and docoahexaenoic acids are biosynthesized from their 18carbon precursors in human infants. Proc Natl Acad Sci USA. 1996;93:49.

[75] SanGiovanni JP, Berkey CS, Dwyer JT, Colditz GA. Dietary essential fatty acids, long-chain polyunsaturated fatty acids and visual resolution acuity in healthy fullterm infants: a systematic review. Early Human Develop. 2000; $57: 165-88$.

[76] Sauerwald TU, Hachey DL, Jensen CL, Chen H, Anderson $\mathrm{RE}$, Heird WC. Intermediates in endogenous synthesis of C22:6 omega 3 and C20:4 omega 6 by term and preterm infants. Pediatr Res. 1997;41:183-7.

[77] Schaeffer L, Gohlke H, Muller M, Heid IM, Palmer LJ, Kompauer I, et al. Common genetic variants of the FADS1
FADS2 gene cluster and their reconstructed haplotypes are associated with the fatty acid composition in phospholipids. Hum Mol Genet. 2006;15:1745.

[78] Sellmayer A, Koletzko B. Long-chain polyunsaturated fatty acids and eicosanoids in infants - physiological and patholphysiological aspects and open questions. Lipids. 1999;34:199-205.

[79] Simmer K. Long chain polyunsaturated fatty acid supplementation in infants form at term. The Cochrane Library. 2004;3:1.

[80] Singhal A, Morley R, Cole TJ, Kennedy K, Sonksen P, Isaacs $\mathrm{E}$, et al. Infant nutrition and stereoacuity at age 4-6 years. Am J Clin Nutr. 2007;85:152.

[81] Smit EN, Martini IA, Mulder H, Boersma ER, Muskiet FE. Estimated biological variation of the mature human milk fatty acid composition. Prostaglandins Leukot Essent Fatty Acids. 2002;66:549.

[82] Stillwell W, Wassall SR. Docosahexaenoic acid: membrane properties of a unique fatty acid. Chem and Phys of Lipids. 2003;126:1.

[83] Szajewska H, Horvath A, Koletzko B. Effect of n-3 longchain polyunsaturated fatty acid supplementation of women with low-risk pregnancies on pregnancy outcomes and growth measures at birth: a meta-analysis of randomized controlled trials. Am J Clin Nutr. 2006;83:1337.

[84] Teller DY. First glances: the vision of infants. Investigative. Ophthalmology \& Visual Science. 1997;38:2183-203.

[85] The Commission of the European Communities. Commission Directive 2006/141/EC of 22 December 2006 on infant formulae and amending Directive 1999/21/EC. Official Journal of the European Union. 30.12.2006:L401/1401/33.

[86] Uauy R, Mena P, Wegher B, Nieto S, Salem N Jr. Long chain polyunsaturated fatty acid formation in neonates: effect of gestational age and intrauterine growth. Pediatr Res. 2000;47:127.

[87] Uauy R, Hoffman DR, Mena P, Llanos A, Birch EE. Term infant studies of DHA and ARA supplementation on neurodevelopment: results of randomized controlled trials. J Pediatr. 2003;143:S17.

[88] Wainwright PE. Dietary essential fatty acids and brain function: a developmental perspective on mechanisms. Proc Nutr Soc. 2002;61:61-69.

[89] Weiler H, Fitzpatrick-Wong S, Schellenberg J, McCloy U, Veitch $\mathrm{R}$, Kovacs $\mathrm{H}$, et al. Maternal and cord blood longchain polyunsaturated fatty acids are predictive of bone mass at birth in healthy term-born infants. Ped Res. 2005; 58:1254-8.

[90] World Health Assembly. Infant and young child nutrition. WHA 54.2, 18 May 2001.

[91] Yuhas R, Pramuk K, Lien EL. Human milk fatty acid composition from nine countries varies most in DHA. Lipids. 2006;41:851-8.

[92] Zeijdner EE, van Houwelingen AC, Kester AD, Hornstra G. Essential fatty acid status of mother and neonate after multiple pregnancy. Prostaglandins Leukot Essen Fatty Acids. 1997;56:395. 